\title{
52. Fusibility of Related Colonies in the Colonial Ascidian, Perophora*)
}

\author{
By Hiromichi Koyama and Hiroshi Watanabe \\ Shimoda Marine Research Center, the University of Tsukuba, \\ Shimoda, Shizuoka 415 \\ (Communicated by Kiyoshi Takewaki, M. J. A., June 12, 1984)
}

In some colonial ascidians, colony specificity is manifested by fusion-incompatibility between two colonies. Some colonies fuse to form a single mass, but others do not. Since Bancroft ${ }^{1}$ first took up this question in Botryllus, the genetic control of colony specificity has been investigated in Botryllus primigenus, ${ }^{2)-4)}$ B. schlosseri, ${ }^{, 5}$ and Monterey Botryllus species. ${ }^{6)}$

Recently, the presence of colony specificity was found in Perophora japonica ${ }^{7}$ ) and $P$. sagamiensis ${ }^{8}$; in each species, two colonies of different origin do not fuse together in almost all combinations, while fragments derived from the same colony always fuse to form a single colony. However, at present, there is no information on the genetic control of the fusibility of these species. Here we present a preliminary report on the fusibility of related colonies of these two species.

Materials and methods. Living colonies of Perophora japonica were collected in the vicinity of the Asamushi Marine Biological Station (Aomori Prefecture) and those of $P$. sagamiensis from Hatakejima Island belonging to the Seto Marine Biological Laboratory (Wakayama Prefecture). These colonies were reared on glass-plates set immersed in the bay near the Shimoda Marine Research Center (Shizuoka Prefecture). During the breeding season, ${ }^{9)}$ larvae were collected from a colony of respective species. After metamorphosis, each oozooid was put on a glass-plate and allowed to grow into a large colony. The fusibility was tested by bringing the natural surfaces of two colonies in contact (see Ref. 7) in detail).

The experiments were carried out at the Shimoda Marine Research Center. It is our pleasant duty to acknowledge our indebtedness to the staff for providing us facilities for carrying out the experiments.

Results and discussion. When two fusible colonies of Perophora japonica come into contact, complete fusion occurs both between the tests and the blood vessels. If two colonies are nonfusible, fusion

*) Contributions from the Shimoda Marine Research Center, no. 429. 
never occurs even between the tests. Table I summarizes the results of fusion experiments among one parental and seven descendant colonies of $P$. japonica. In this case, all seven combinations between the parent and its descendant were nonfusible. In the twenty-one combinations among descendant colonies, only two combinations were fusible.

Table I. The fusibility between parental and seven descendant colonies of $P$. japonica

\begin{tabular}{lrrrrrrrr}
\hline & $\mathrm{p}$ & $\mathrm{d} 1$ & $\mathrm{~d} 2$ & $\mathrm{~d} 3$ & $\mathrm{~d} 4$ & $\mathrm{~d} 5$ & $\mathrm{~d} 6$ & $\mathrm{~d} 7$ \\
\hline $\mathrm{p}$ & $\mathrm{f}$ & & & & & & & \\
$\mathrm{d} 1$ & $\mathrm{nf}$ & $\mathrm{f}$ & & & & & & \\
$\mathrm{d} 2$ & $\mathrm{nf}$ & $\mathrm{nf}$ & $\mathrm{f}$ & & & & & \\
$\mathrm{d} 3$ & $\mathrm{nf}$ & $\mathrm{nf}$ & $\mathrm{nf}$ & $\mathrm{f}$ & & & & \\
$\mathrm{d} 4$ & $\mathrm{nf}$ & $\mathrm{nf}$ & $\mathrm{nf}$ & $\mathrm{nf}$ & $\mathrm{f}$ & & & \\
$\mathrm{d} 5$ & $\mathrm{nf}$ & $\mathrm{nf}$ & $\mathrm{nf}$ & $\mathrm{nf}$ & $\mathrm{nf}$ & $\mathrm{f}$ & $\mathrm{f}$ & \\
$\mathrm{d} 6$ & $\mathrm{nf}$ & $\mathrm{nf}$ & $\mathrm{f}$ & $\mathrm{nf}$ & $\mathrm{nf}$ & $\mathrm{nf}$ & $\mathrm{nf}$ & $\mathrm{f}$ \\
$\mathrm{d} 7$ & $\mathrm{nf}$ & $\mathrm{f}$ & $\mathrm{nf}$ & $\mathrm{nf}$ & $\mathrm{nf}$ & $\mathrm{nf}$ & $\mathrm{nf}$ & \\
\hline
\end{tabular}

p, parental colony; d1-d7, descendant colonies; f, fusion; nf, nonfusion.

In $P$. sagamiensis, two types of nonfusion were found and they were termed "nonfusion type A" and "nonfusion type B", respectively. ${ }^{8)}$ In nonfusion type $A$, two colonies reject each other without fusion between their tests; while in nonfusion type $B$, rejection occurs after a transitory fusion of the tests. The fusibility among one parental and five descendant colonies was examined (Table II). In this experiment, all five combinations between the parent and its descendants produced nonfusion type B. In the combinations among descendant colonies, all possible reactions were found.

Table II. The fusibility between parental and five descendant colonies of $P$. sagamiensis

\begin{tabular}{ccccccc}
\hline & $\mathrm{p}$ & $\mathrm{d} 1$ & $\mathrm{~d} 2$ & $\mathrm{~d} 3$ & $\mathrm{~d} 4$ & $\mathrm{~d} 5$ \\
\hline $\mathrm{p}$ & $\mathrm{f}$ & & & & & \\
$\mathrm{d} 1$ & $\mathrm{nf} \mathrm{B}$ & $\mathrm{f}$ & & & & \\
$\mathrm{d} 2$ & $\mathrm{nf} \mathrm{B}$ & $\mathrm{nf} \mathrm{B}$ & $\mathrm{f}$ & & & \\
$\mathrm{d} 3$ & $\mathrm{nf} \mathrm{B}$ & $\mathrm{nf} \mathrm{B}$ & $\mathrm{nf} \mathrm{B}$ & $\mathrm{f}$ & & \\
$\mathrm{d} 4$ & $\mathrm{nf} \mathrm{B}$ & $\mathrm{nf} \mathrm{B}$ & $\mathrm{nf} \mathrm{B}$ & $\mathrm{nf} \mathrm{B}$ & $\mathrm{f}$ & \\
$\mathrm{d} 5$ & $\mathrm{nf} \mathrm{B}$ & $\mathrm{nf} \mathrm{B}$ & $\mathrm{f}$ & $\mathrm{nf} \mathrm{A}$ & $\mathrm{nf} \mathrm{A}$ & $\mathrm{f}$ \\
\hline
\end{tabular}

$\mathrm{p}$, parental colony; d1-d5, descendant colonies; f, fusion; nf A, nonfusion type A; nf B, nonfusion type B.

In some species of Botryllus, the fusibility was shown to be controlled by a multiallelic single locus. ${ }^{2-6)}$ In these species, two colonies must share at least one allele in order to fuse together. As 
for the test of $P$. sagamiensis, the parent and each of its descendants were fusible. Among the descendants, fusible and nonfusible combinations were obtained, as among related colonies of Botryllus primigenus. ${ }^{2-4)}$ However, in P. sagamiensis, the blood vessels of the parent and its descendants were never fusible. Moreover, in $P$. japonica, even the tests of the parent and its descendants never fused together. These observations suggest that the control mechanisms of the fusibility in $P$. japonica and $P$. sagamiensis are not the same as that in $B$. primigenus. For example, these fusibilities may be controlled by several loci. If the fusibilities of $P$. japonica and $P$. sagamiensis are also controlled by a multiallelic single locus as in the case of $B$. primigenus, it might be necessary for two colonies of each species to share both allele in order to fuse together. In order to clarify the control mechanisms of the present two species, further genetic analysis is needed.

This work was supported by Grants-in-Aid for Special Research 310605 and for Scientific Research 248018 to H. Watanabe from the Ministry of Education, Science and Culture of Japan.

\section{References}

1) Bancroft, F. W. (1903): Proc. Calif. Acad. Sci., 3, 137-186.

2) Oka, H., and Watanabe, H. (1957): Proc. Japan Acad., 33, 657-659.

3) - (1960): Bull. Mar. Biol. Asamushi, Tôhoku Univ., 10, 153-155.

4) - (1967): Kagaku (Tokyo), 37, 307-313.

5) Sabbadin, A. (1982): Amer. Zool., 22, 756-773.

6) Scofield, V. L., Schlumpberger, J. M., and Weissman, I. L. (1982) : ibid., 22, 783-794.

7) Koyama, H., and Watanabe, H. (1981) : Annot. Zool. Jap., 54, 30-41.

8) - (1982): Biol. Bull., 162, 171-181.

9) Mukai, H., Koyama, H., and Watanabe, H. (1983) : ibid., 164, 251-266. 